\title{
A Fuzzy Controller Based SAPF for Power Quality Enhancement of Distribution System Integrated with Wind Energy Source
}

\author{
Vikas Kumar Sharma*, Lata Gidwani \\ Electrical Engineering Department, Rajasthan Technical University, Kota, 323021, India
}

\begin{tabular}{l} 
A R T I C L E I N F O \\
\hline Article history: \\
Received: 08 September, 2020 \\
Accepted: 01 November, 2020 \\
Online: 10 November, 2020 \\
\hline Keywords: \\
Wind energy \\
Distribution System \\
Power quality \\
Fuzzy controller \\
APCT \\
SAPF
\end{tabular}

\begin{abstract}
A B S T R A C T
Wind energy is emerged rapidly as the most important and viable sustainable power source due to the mature technology and wide availability. The integration of wind energy sources and utilization of nonlinear loads having different characteristics results in several challenges in a distribution system. One of which is power quality issue. Hence, in this work, the impact of power quality issues in a distribution system integrated with the wind generation system is studied in the uses of a shunt active power filter (SAPF) and presence of non-linear load conditions. The realization of SAPF is carried out using active power component theory (APCT) for reference current extraction, proportional-integral (PI) controller, and fuzzy logic controller (FLC) for dc-link voltage regulation and a basic hysteresis band current controller method for the extraction of switching pulse for operational the inverter. To enhance power quality in the proposed system, a modified fuzzy logic-controlled (MFLC) is developed to improve the transient performance of shunt APF. The proposed model is developed in MATLAB and results are given so as to show the presentation of the performance of this compensation technique in terms of mitigation of system harmonics, reactive power compensation, and enhancing the power factor.
\end{abstract}

\section{Introduction}

This Electrical energy has become an integral part of human life and its use is increasing globally by leaps and bounds to improve the living standard. Global concern of utilization of green and clean energy sources for sustainable power systems and shortage of fossil fuel reserves create opportunities for renewable energy sources (RES) of generation. In this manner, the expanding dangers to the earth from the vitality created by the broad utilization of fossil fuels have left us with the thought of renewable energy sources (RES) as the main conceivable arrangement. The demand for sustainable power sources has highly increased due to a lack of fossil fuel, environmental impact and global warming problems of the world. The classification and trends of wind energy chnology has been discussed [1-4] in detail. Wind power is the most developing, promising, and viable sustainable power source that has been dissipated over the word, and utilization of this energy source has been expanding vary large scale. The integration of distributed generation (DG) is directed to increments in vitality productivity and a decrease in emission. The ever-increasing load demand and scarcity of electric power have attracted the attention of power engineers to

${ }^{*}$ Corresponding author: Vikas Kumar Sharma., vikasvs1985@ gmail.com evolve the new techniques for the effective utilization of electrical energy. Such evolutions have increased the use of power electronics devices and controllers in manifold over the last two decades for more efficient operation of the electrical equipment and to transfer more power through the power networks, but they degrade the power quality in the distribution network connected with wind generation source.

The PQ problem of grid-connected wind energy conversion has been discussed [5-8] by many authors in past years. In [9], the author discussed the power quality issues related to flicker, reactive power, current harmonic distortion, stability of wind generator during the faulty conditions. Further, there are a lot of disturbances that create PQ problems such as harmonics distortion, voltage interruption, transient disturbances, frequency variations, etc. Out of these disturbances the main polluting impact will be created by harmonic distortion but at the same time, it does not mean that power conditioning is only confined to harmonic filtering. In [10], the author introduced the power electronics devices to operate on the sinusoidal voltage but they inject harmonics in the power system networks and increase reactive power demand. The injected harmonics are responsible for the distortion of voltage and current waveshapes. These nonlinear 
loads are a big reason of harmonics, and extra neutral currents in the power system network. In [11], the author reviewed the different sources of customer- generated harmonics include AC/DC converters adjustable speed drives, switching power supplies, AC phase control circuit, cyclo converters, magnetizing current of transformer, arc furnaces, welding machines, traction systems, switch-mode power supplies (SMPS), computers and programmable logic controllers (PLC's), etc. Moreover, the single-phase loads like personal computers (PCs), fluorescent lights, printers, Xerox machine, television, etc. are also responsible for excessive neutral current distribution system.

The capability and use of SAPF has been investigated in [1214]. A SAPF could be used as the potential solution to mitigate the utility current disturbances and enhancing power quality in power distribution system integrated with wind generation system. The shunt connected custom power devices are especially useful to maintain power factor, balancing of load, limitation of harmonics and voltage regulation at distribution voltage level, etc. The SAPF operated in the current control mode is capable of injecting negative harmonic current into the grid. Hence, in today's scenario, active power is popular and preferred over the passive filter. Shunt APF has the ability to mitigate the current harmonics from the system but series has sued for voltage harmonics. In [15], the author discussed for fast and precise estimation of reference current, predictive and adaptive controllers based on the neural network have been proposed. The quick estimation of compensating currents a lot of artificial and soft computing techniques was used. Because of the added advantage of ANN to compute the Fourier series coefficient the authors have preferred this over others improved hysteresis current controller technique is overcome wide variation of switching frequency, hence, reduce the switching frequency. In [16], the author implemented a lot of on the hysteresis based current controller in literature like as adaptive frequency domain control of PWM strategy, three-dimensional PWM technique, etc.

In [17], the author developed a standalone wind-diesel hybrid system, in which an active shunt filter is introduced to mitigate the harmonics of load current. In [18-19], they are presented the recent work on the grid integration of renewal energy with SAPF for current harmonic elimination. The dc-link voltage control is achieved by either PI or fuzzy logic technique in SRF based SAPF for proposed system. In [20], the author discussed the purpose of analysis the harmonic reduction and SAPF control technique using harmonic extractor-based method to renewable energy source integrated with grid. In [21], the author proposed the SRF reference current method based shunt active power filter with PI controller to mitigate the current harmonics from the grid connected wind at PCC simultaneously non-linear load conditions. In [22], the author implemented the ICC controller is proposed for shunt active filter for enhance power quality in renewable source interfaced grid system. In [23], the author proposed the system performance parameter like output voltage, frequency and THD level at variable wind speed and nonlinear load conditions. The validity of proposed SAPF is analyzed with fuzzy logic based PWM technique. In [24], the author implemented a technique for reduce of harmonics in hybrid SAPF connected distribution network to enhance the power quality. The optimal controller was made by the improved optimization algorithm.
The recent literatures on the grid integration of wind energy with SAPF mainly focus on the study of current harmonics reduction by the grid current THD analysis. However, a smaller number of publications had been reported for proposing distribution grid level implementation of SAPF for power quality enhancement with the integration of wind energy source. Hence, there is a need to investigate the methods which may be implemented at the grid level to mitigate the power quality problem due to wind energy into the distribution grid. The performance of APC- PI theory with direct and indirect current control methods are compared and found that in both conditions, the neutral current compensation is almost same but the remarkable improvement is observed in power factor, reactive power compensation and load balancing with indirect control method. It is proved through proposed simulation that the indirect current control method performance is better than direct current control for the distribution grid integrated with wind generation system. So, proposed Indirect APC-MFLC methods are suitable to compensate harmonics and reactive power, neutral current during unbalanced loading conditions. The system is capable of maintaining unity power factor as well as sinusoidal source currents. Hence, the power quality of distribution system is improved.

The major contributions of this paper are integration and design of APCT based SAPF in proposed system for enhances the power quality problem. The proposed MFLC controller strategy is validated through APC theory by extensive simulation results for enhancement in overall power quality problem of the proposed system. This paper is classified in five sections, first is the introduction in Section 1. Section 2 mathematical modeling and detail of the proposed model and proposed SAPF control method in Section 3, simulation result and discussion presented in Section 4. The conclusion is shown in Section 5.

\section{Proposed Model}

A PMSG based wind energy connected through AC-DC-AC converter to distribution grid with a non-linear load connected to load bus shown in Figure 1. A shunt APF connected with the system for enhancement of power quality in non-linear loading conditions and PMSG integrated with the grid. The proposed system is not only capable of transfer the wind energy to the grid, but will also act as a shunt active power filter (SAPF) to mitigate the current harmonics and regulate reactive power feed by the nonlinear loads. Table 1 provides parameter of wind turbine and PMSG.

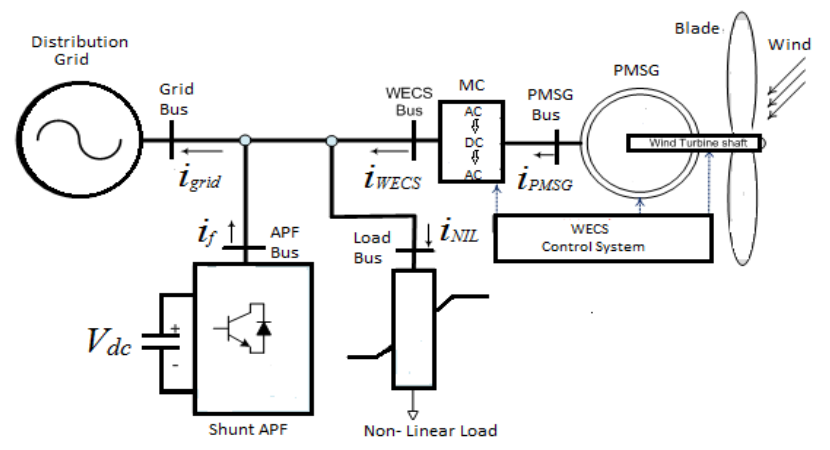

Figure 1: Block Diagram of Distribution Grid- Integrated Wind Generation System with Shunt APF and Non-linear Load. 
A. Modeling of Wind Turbine System

The wind speed is sum of these components.

$$
V_{w}(t)=V_{B}(t)+V_{N}(t)+V_{G}(t)+V_{R}(t)
$$

where, $V_{w}$ is the wind speed, all of them in "meter/ second" and time $\mathrm{t}$ is in "second Here this wind speed signal have four component, i.e. the basic speed of wind $\left(V_{B}\right)$, a fluctuating wind $\left(V_{N}\right)$ that describes a steady increase in wind speed, gust component $\left(V_{G}\right)$ and a gradient wind component $\left(V_{R}\right)$. The mechanical energy given wind turbine is determined as follow [3]

$$
P_{\text {wind }}=\frac{1}{2} C_{p}(\lambda, \beta) \pi r^{2} \rho_{\text {air }} V_{w}^{2}
$$

Power coefficient $\left(C_{p}\right)$ is the ratio of mechanical power generated by the turbine to the power available in the wind. Which $\lambda$ is the tip speed ratio, $C_{p}$ is given as [3]

$$
C_{p}=c_{1}\left(c_{2} \frac{1}{\alpha}-c_{3} \beta-c_{4} \beta^{x}-c_{5}\right)
$$

$\beta$ is a function of the pitch angle of rotor blades, when $\beta$ is equal to zero.

$$
\frac{1}{\alpha}=\frac{1}{\lambda+0.08 \beta}-\frac{0.035}{1+\beta^{2}}
$$

Therefore, the tip speed ratio can be given as [3]

$$
\lambda=\omega_{a} r / V_{w}
$$

The mechanical torque turbine is defined as follow [3]

$$
T_{\text {mech }}=\frac{0.5 C_{p} \pi r^{2} \rho_{a i r} V_{w}^{2}}{\omega_{a}}
$$

The driven train is treated as one concentrated mass model to time efficiency and precision. It is defined as:

$$
\frac{d}{d t} \omega_{a}=\frac{1}{j}\left(T_{\text {mech }}-T_{\text {elect }}-B_{x} \omega_{a}\right)
$$

where, $\mathrm{B}_{\mathrm{x}}$ is damping coefficient, $\omega_{\mathrm{g}}$ is angular speed $(\mathrm{rad} / \mathrm{sec})$, $\mathrm{T}_{\text {elect }}$ is the electromechanical torque $(\mathrm{Nm}), \mathrm{T}_{\text {mech }}$ is the aerodynamic torque and $\mathrm{J}$ equivalent rotational inertia of the generator $\left(\mathrm{kg}-\mathrm{m}^{2}\right)$

\section{B. Modeling of PMSG}

The direct axis and quadrature axis voltage equation of generator is define as

$$
\begin{gathered}
V_{d} \equiv-R_{s} i_{d}-L_{d} \frac{d i_{d}}{d t}+\omega_{e} L_{q} i_{q} \\
V_{q} \equiv-R_{s} i_{q}-L_{q} \frac{d i_{q}}{d t}-\omega_{e} L_{d} i_{d}+\omega_{e} \mu_{g}
\end{gathered}
$$

$\omega_{e}$ is the rotor speed in $\mathrm{rad} / \mathrm{s}$ of the generator, describe by

$$
\omega_{e}=\omega_{a} P
$$

The electromagnetic torque of PMSG is given by

$$
T_{\text {elect }}=\frac{3}{4} P\left[\mu_{g}+\left(L_{d}-L_{q}\right) i_{d}\right] i_{q}
$$

Then, the angular speed of generator is defined as [4]:

$$
\frac{d}{d t} \omega_{a}=\frac{1}{j}\left(T_{m e c h}-T_{\text {elect }}-B_{x} \omega_{a}\right)
$$

Table 1: parameter of wind turbine \& generator

\begin{tabular}{|l|l|}
\hline Parameter & Value \\
\hline Generated Power, $(P)$ & $2 \mathrm{MW}$ \\
\hline Stator Resistance $\left(R_{s}\right)$ & $0.7305 \mathrm{~m} \Omega$ \\
\hline Stator d-axis Inductance $\left(L_{d}\right)$ & $1.21 \mathrm{mH}$ \\
\hline Stator q-axis Inductance $\left(L_{q}\right)$ & $2.31 \mathrm{mH}$ \\
\hline Permanent Magnet Flux $\left(\mu_{g}\right)$ & $6.61 \mathrm{~Wb}$ \\
\hline Inertia $\left(J_{\text {eq }}\right)$ & $10000 \mathrm{~kg} \cdot \mathrm{m}^{2}$ \\
\hline Radius of Blades $(r)$ & $38 \mathrm{~m}$ \\
\hline Air Density $(\rho)$ & $1.205 \mathrm{~m}^{3}$ \\
\hline
\end{tabular}

\section{Proposed Control Method for SAPF}

The Voltage Source Inverter has seen widely utilized in shunt APF setup to minimize power quality issues. It is also utilized for energy storage during ideal system conditions, but the charging and discharging of this capacitor controlled utilized a control theory. Hence, only the active filter fit for producing counter harmonic current and feeding the reactive power to point of common coupling (PCC). Figure 2 presents the configuration of the proposed shunt APF with a distribution system integrated into the wind energy conversion system (WECS). The main aim of proposed method is to evaluate the control strategy for current harmonics reduction, compensation of reactive power and balancing of load current at PCC when the supply current is distorted.

\subsection{Active Power Component (APC) or Unit Vector Template Theory}

Shunt APF can effectively handle the harmonics and reactive power problems simultaneously. Presently shunt APFs are designed to encounter all the harmonics which is generated by nonlinear loads but the distribution system is highly unbalanced, so it is required to mitigate the neutral current burden and make the source current sinusoidal for the calculation of the desired compensation current. The unit vector templates are determined as

$$
\begin{gathered}
U_{a}=\frac{v_{S a}}{V_{S P}}=\sin \theta \\
U_{b}=\frac{v_{S b}}{V_{S P}}=\sin \left(\theta-120^{\circ}\right) \\
U_{c}=\frac{v_{S c}}{V_{S P}}=\sin \left(\theta+120^{\circ}\right)
\end{gathered}
$$

In a three-phase system, it is represented as $i_{a}^{*}, i_{b}^{*}$, and $i_{c}^{*}$. Neutral current ought to be zero, along these references neutral current taken as zero in a balanced system. Capacitor voltage error goes 


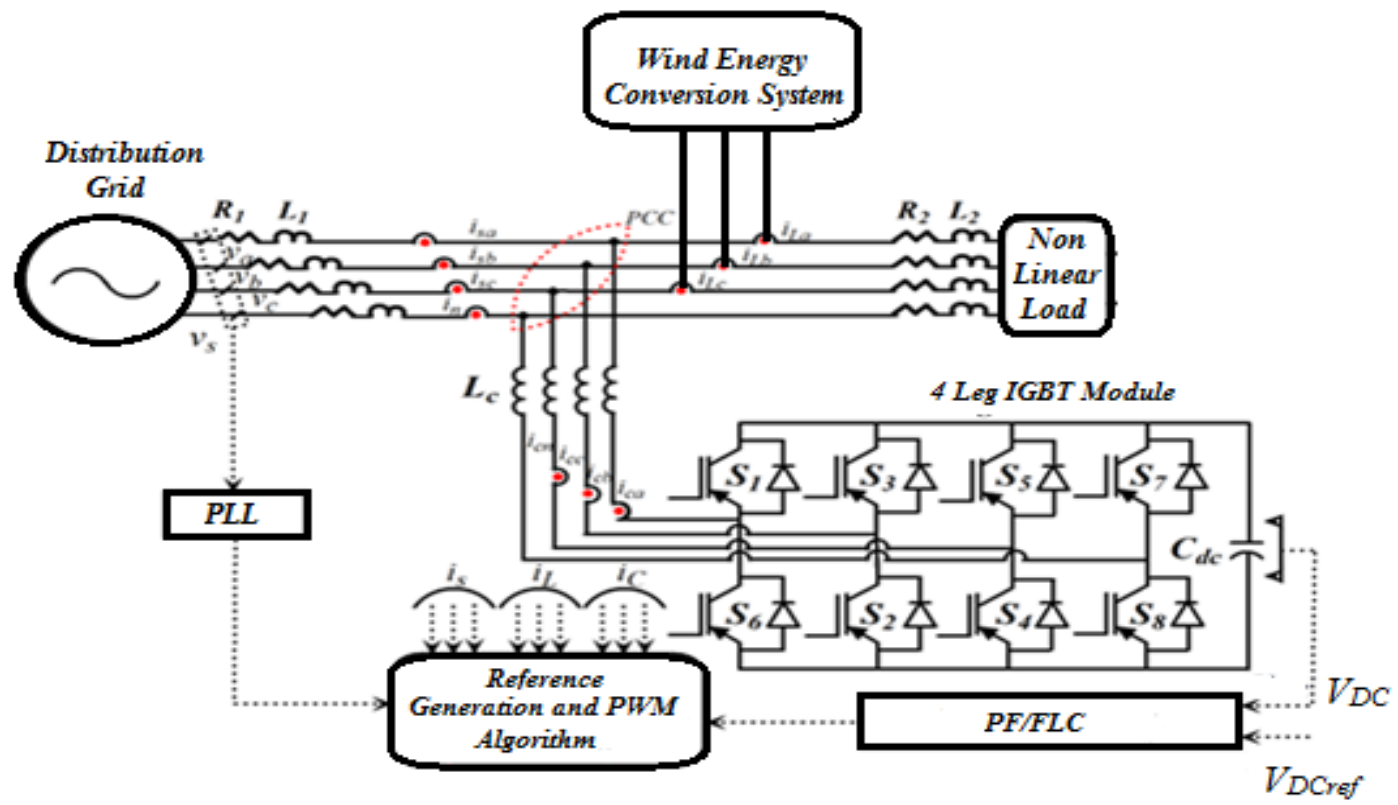

Figure 2: Proposed Shunt APF Configuration with Distribution System

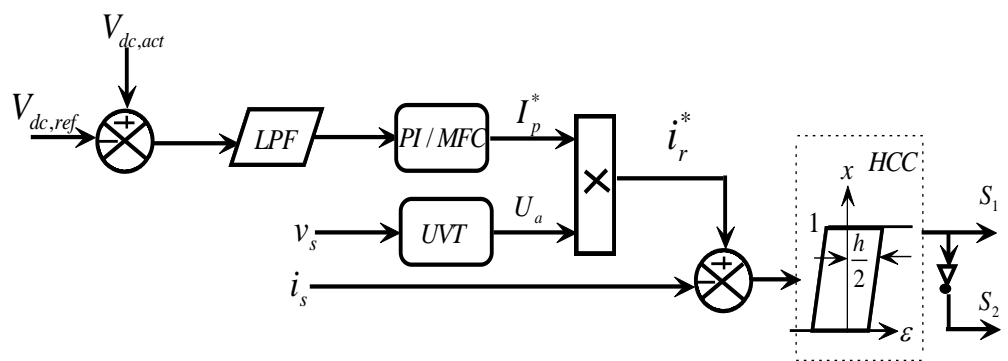

Figure 3: Block Diagram of UVT/APCT Algorithm with Indirect Current Control Method

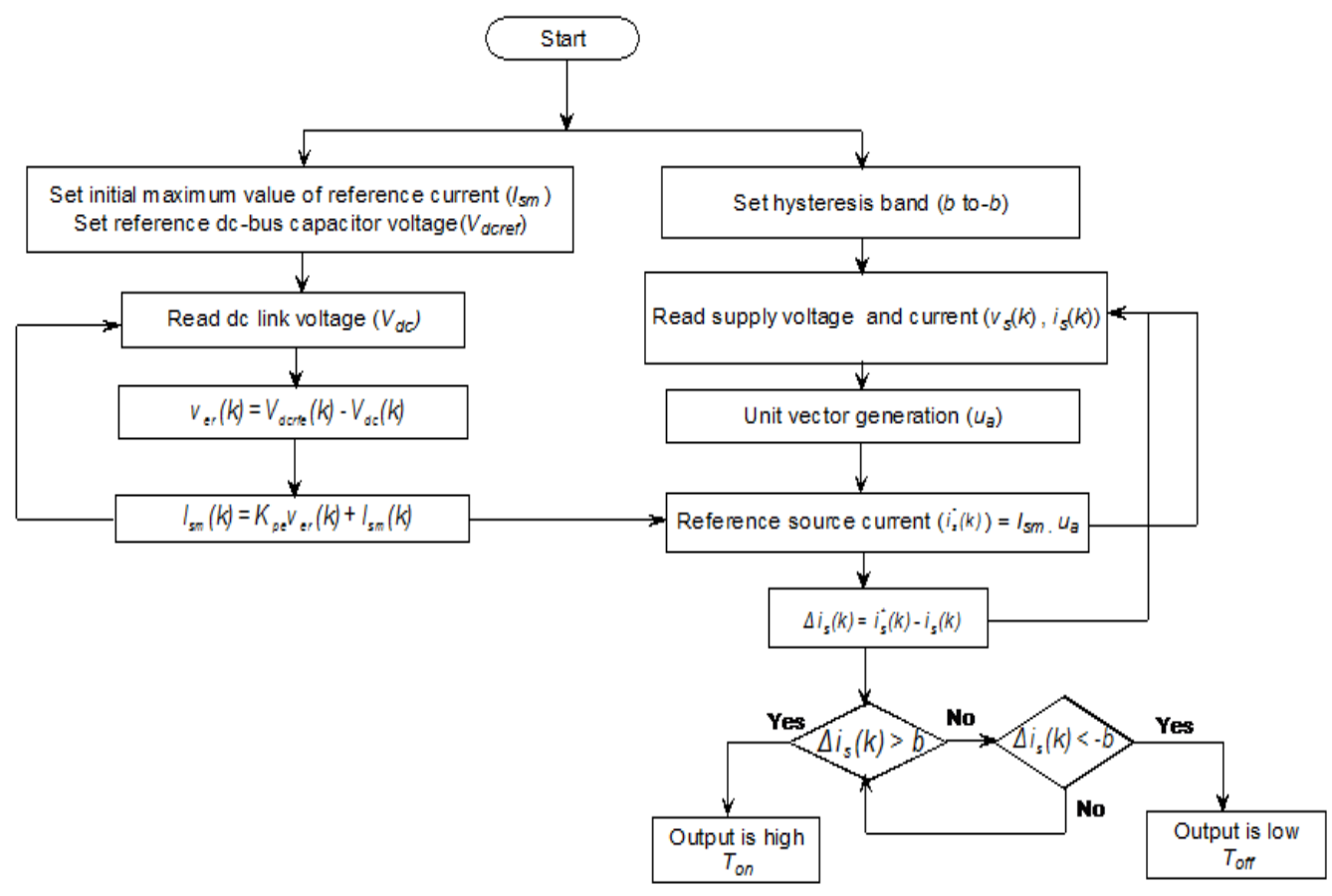

Figure 4: Flowchart of Active Power Component Theory (APCT) Algorithm 
through the low power filter. The filtered dc voltage is contrasted with the reference value. Reference current can be composed as

$$
i_{a}^{*}=I_{m} U_{a}, \quad i_{b}^{*}=I_{m} U_{b}, \quad i_{c}^{*}=I_{m} U_{c}, i_{n}^{*}=I_{m} U_{n}
$$

As present in the Figure 3 that capacitor voltage error goes through the LPF, which remove the high-frequency ripple from the voltage. This filtered dc voltage is compared with the reference value. Now error between the reference and grid current is processed by utilizing the following equations

$$
\left.\begin{array}{c}
i_{a}^{*}=I_{m} U_{a} \\
i_{b}^{*}=I_{m} U_{b} \\
i_{c}^{*}=I_{m} U_{c} \\
\text { and } \\
i_{n}^{*}=I_{m} U_{n}
\end{array}\right\}
$$

Figure 4 presents the flowchart of the APCT algorithm with indirect current control method.

\subsection{DC voltage Controller}

DC voltage controller calculates response of the model and increasing proportional above a value can generate swaying. Integral control expels the error from the output. To actualize the PI controller, the dc link voltage is estimated the reference value. The transfer function of the PI-controller is given from [18] as follows

$$
H(s)=\left(k_{i} / S\right)+k_{p}
$$

For the usage of the fuzzy rule over the PI controller in close loop filter, the dc voltage signal is compared with reference signal and reference error will be produced as follow [18]:

$$
e=V_{\mathrm{dc}, \text { reference }}-V_{\mathrm{dc}, \text { actul }}
$$

The reference for $\mathrm{n}^{\text {th }}$ sampling time is taken as a change of error in fuzzification process is determining as follows [18]-[19]

$$
C_{e(n)}=e(n)-e(n-1)
$$

\subsection{Proposed Fuzzy Ligic controller}

The proposed modified fuzzy logic controller (MFLC) of the system is used to control the response of the dc voltage. They can be defined, as

$$
\begin{aligned}
& x=\left(x_{i}, U_{i},\left\{T_{x_{i}}^{1}, T_{x_{i}}^{2}, \cdots, T_{x_{i}}^{k_{i}}\right\},\left\{\mu_{x_{i}}^{1}, \mu_{x_{i}}^{2}, \cdots, \mu_{x_{i}}^{k_{i}}\right\}\right) \\
& \quad \text { for } i=1,2, \cdots, n \\
& y=\left(y_{i}, V_{i},\left\{T_{y_{i}}^{1}, T_{y_{i}}^{2}, \cdots, T_{y_{i}}^{l_{i}}\right\},\left\{\mu_{y_{i}}^{1}, \mu_{y_{i}}^{2}, \cdots, \mu_{y_{i}}^{l_{i}}\right\}\right) \\
& \text { for } i=1,2, \cdots, m
\end{aligned}
$$

where $x \& y$ is the input \& output linguistic variable form a fuzzy output space. The size of a term set, $T_{(x i)}=K_{i}$ is called as the fuzzy partition number of $X_{i}$. In the case of a two - input-one-output proposed MFC system, If $T_{(x 1)}=9$ and $T_{(x 2)}=9$, than the number of fuzzy control rules is $9 \times 9$. A bell shaped relationship function has been used.

$$
\mu_{x i}(x)=\exp \left(-\frac{\left(x-m_{i}\right)^{2}}{\sigma_{l}{ }^{2}}\right)
$$

This modified fuzzy controller rules are developed and approved dependent on AND Boolean logic operator. The new rules are characterized by fundamental stability position and moment in time response. To use of fuzzy sets, we restructure operators of the standard set method to fit the particular relationship functions of fuzzy logic for a value between zero $\&$ one. Here two variables are utilized as a contribution of MFLC, first is Error $E$ and second change of error $C_{e}$. The moment in time response has been divided into four regions $A_{1}, A_{2}$, and $A_{3}, A_{4}$ with two arrangements of point, first is the peak value index $\left(b_{1}, b_{2}\right)$, and second cross over-index $\left(c_{1}, c_{2}\right)$. The fuzzy operator AND is formed from a grouping of fuzzy prepositions. Based on the above theory, rules are defined as ZE, PN NB, NS NM, PS, PB, and PB, $\mathrm{PM}$ for processing the dc-link response shown in Table 2. Figure 5 shows the moment in time response of a stable closed loopsystem.

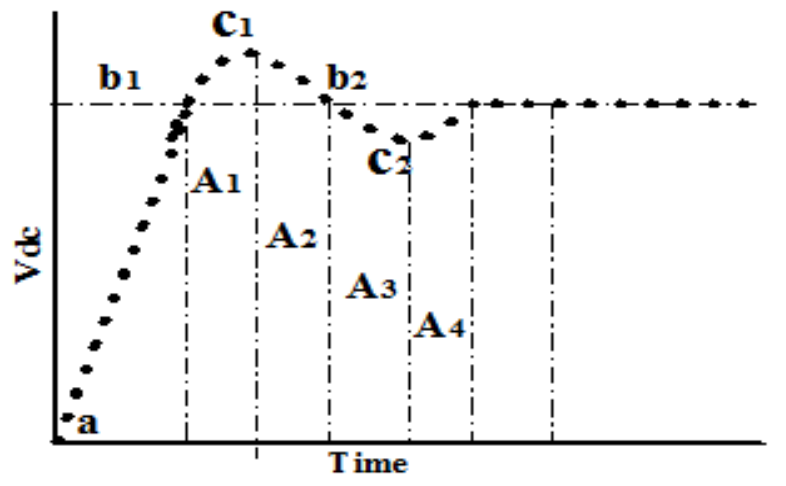

Figure 5: Moment in Time Response of a Stable Closed Loop System.

Table 2: Mechanism of Proposed modified fuzzy rule

\begin{tabular}{|l|c|c|c|c|c|c|c|c|c|}
\hline $\begin{array}{l}\text { Error/ } \\
\text { Change } \\
\text { error } \\
(\mathbf{E}) /(\mathbf{C e})\end{array}$ & NB & NM & NS & NN & ZE & PN & PS & PM & PB \\
\hline NB & NB & NB & NB & NB & NB & NB & NB & NM & ZE \\
\hline NM & NB & NB & NM & NM & NM & NM & NS & ZE & PM \\
\hline NS & NB & NM & NM & NS & NS & NS & ZE & PS & PM \\
\hline NN & NB & NM & NS & NN & ZE & ZE & PS & PM & PB \\
\hline ZE & NB & NS & NS & ZE & PN & PN & PS & PM & PB \\
\hline PN & NS & NB & NS & PN & PS & PS & PS & PM & PB \\
\hline PS & NM & NS & ZE & PS & PS & PS & PM & PM & PB \\
\hline PM & NB & ZE & PS & PM & PM & PM & PM & PB & PB \\
\hline PB & ZE & PM & PB & PB & PB & PB & PB & PB & PB \\
\hline
\end{tabular}




\section{Result and discussion}

The performance analysis of the distribution grid integrated with wind generation system is study with proposed SAPF under the use of different controllers for unbalanced loading condition. The impact of PQ issues in a distribution grid integrated with wind generation system is investigated in the presence of SAPF. The effectuation of SAPF is carried out using active power component theory (APCT) for reference current generation with direct and indirect current control method. Proportional integral (PI) controller is proposed with modified fuzzy logic controller (MFLC) for dc link voltage regulation and a basic hysteresis band current controller method. For study state analysis purposes, the load change with an increase at $t=1.2 \mathrm{sec}$, and again it is changed with decreasing at $t=2.3 \mathrm{sec}$. The RMS load current at $t=0.2 \mathrm{sec}$ is in phase "a" 139.2 Amp, phase "b" 103 Amp, and in phase "c" 68.8 Amp. This result presents the unbalanced condition in the distribution system. Without compensation the neutral current flow in 73.3 Amp, the reactive power drawn is $20 \mathrm{kVAR}$, power factor degradation is below 0.8 , and load current THD is $22.50 \%$. A SAPF with a hysteresis-based APC technique is used to enhance the performance of the system according to certain power quality standards. In this technique, the reference signal is compared with actual utility load current.

\subsection{Case 1: Direct current control with APCT-PI}

In the direct current control method with APCT-PI, the switching pulses are generated through hysteresis controller by comparing the sensed three phase shunt APF current with their computerized generated reference current signal. The performance of the direct current control method with the APCT technique as shown in figure 6 . The following observation has been made out after compensation reactive power flow between souse and load is $7 \mathrm{KVAR}$, natural current is around $7 \mathrm{Amp}$ and system power factor is nearly 0.94 .

\subsection{Case 2: Indirect current control with APCT-PI}

In the indirect current control method, the PWM switching pulses are obtained by comparing the sensed three phase current with their reference current which are generated by the reference current extraction methods. The performance of the in-direct current control method with the APCT technique is shown in figure 7. The following observation is made out after compensation reactive power flow between souse and load is 6 KVAR, natural current is around $6.8 \mathrm{Amp}$ and system power factor is nearly 0.996. Hence the performance of the in-direct current control loop with unit vector template theory is found better than direct control so modified FLC implanted on indirect current method.

\subsection{Case 3: Indirect current control with Modified Fuzzy Logic controller with APCT}

It provides the batter result in a comparison of harmonics mitigation, reactive power compensation, and power factor improvement. From the figure 8, following observation, has been made out after compensation reactive power flow between souse and load is 3.7 KVAR, natural current is around 4.7 Amp and system power factor is nearly 0.999 . Hence the performance of the in-direct current control loop with MFLC based APC theory is found suitable for SAPF. The comparisons of harmonics mitigation are shown in figure 9.

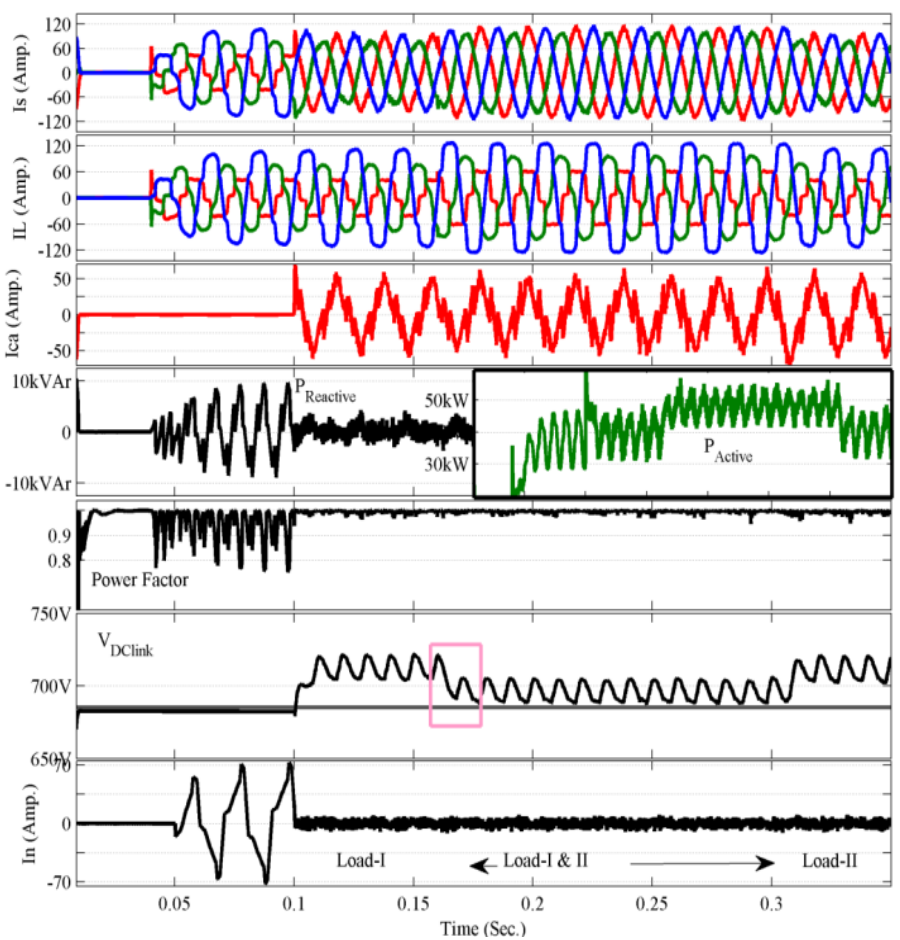

Figure 6: Indirect current control method shown as $I_{\text {sourse }}, I_{\text {load }}, I_{\text {netural }}, P_{\text {react., }} \mathrm{PF}$, $V_{\mathrm{DC}}$ and $I_{n}$ with APC-MFLC theory.

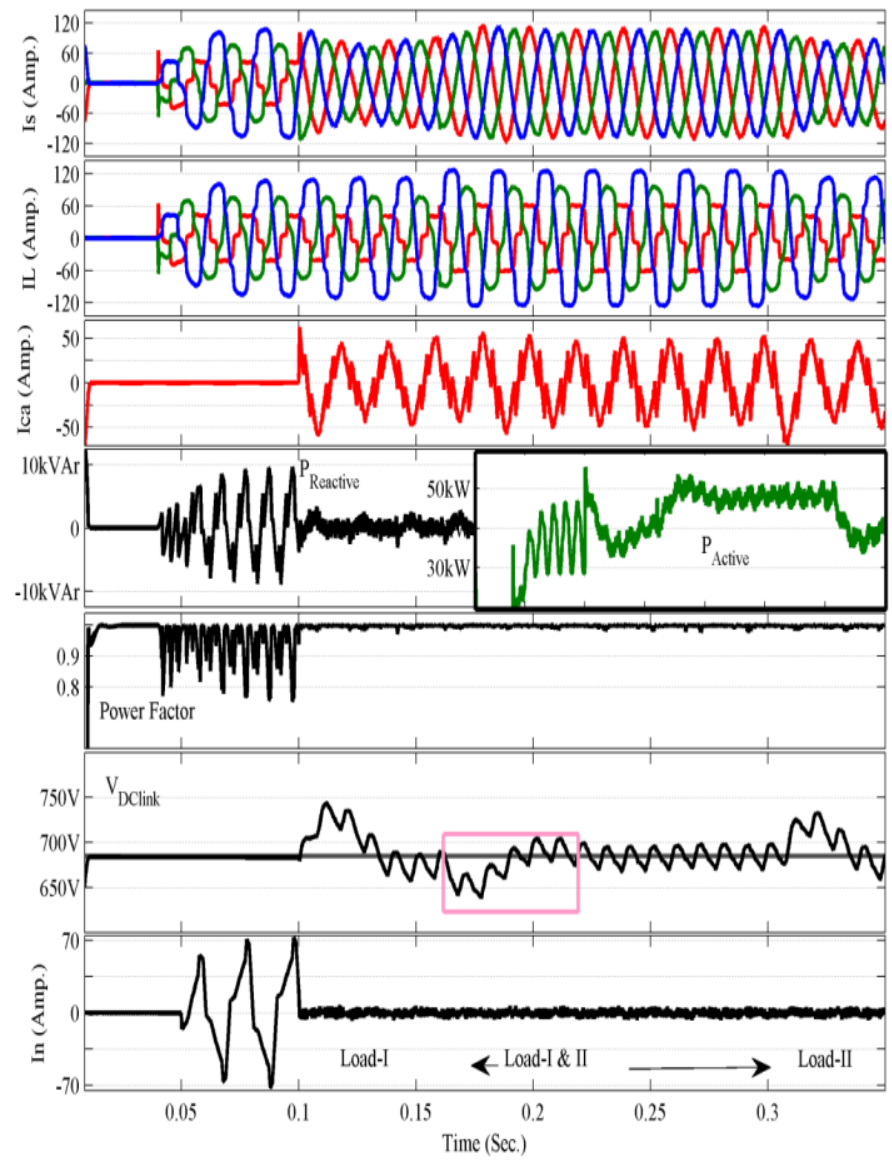

Figure 7: Direct current control method shown as $I_{\text {sourse },} I_{\text {load, }} I_{\text {netural }}, P_{\text {react., }}, P F, V_{\mathrm{DC}}$ and $I_{n}$ with APC-PI theory. 


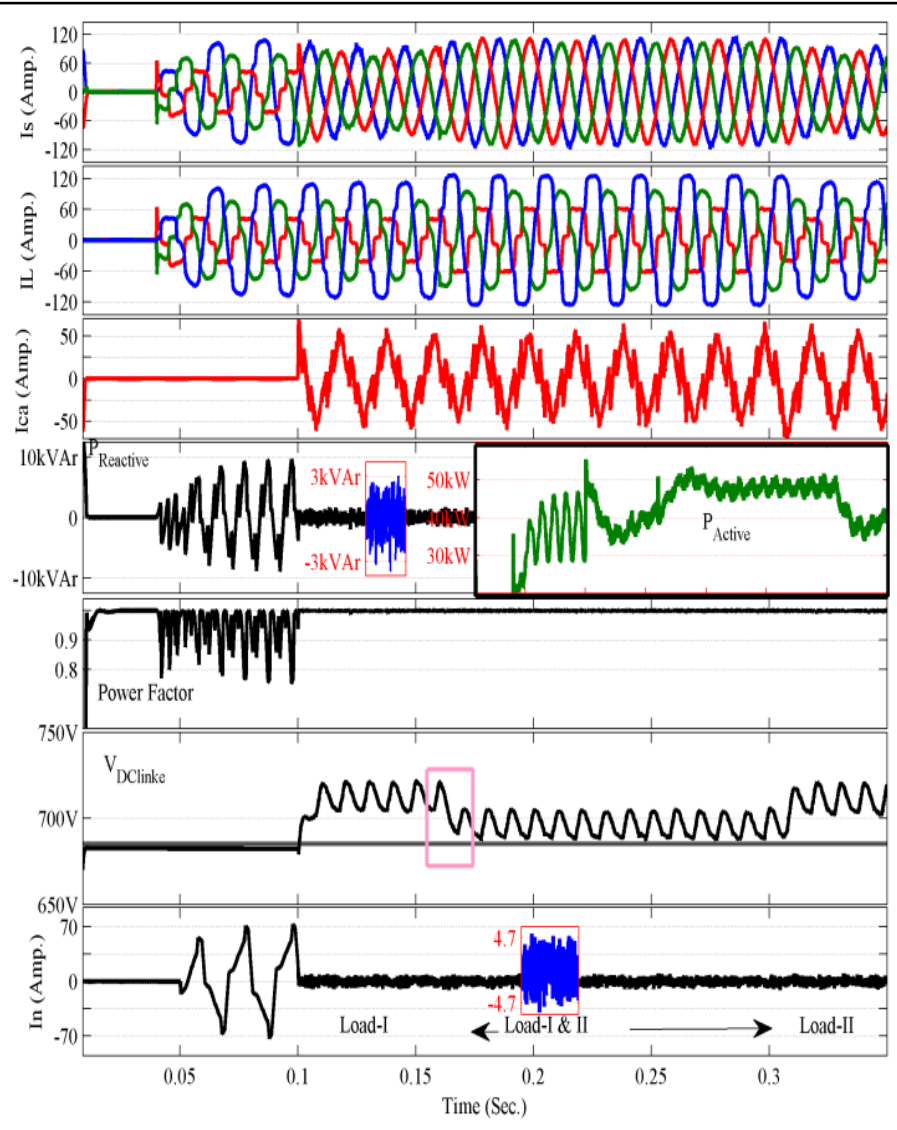

Figure 8: Indirect current control method shown as $I_{\text {sourse },} I_{\text {load }}, I_{\text {netural, }} P_{\text {react., }} \mathrm{PF}$, $V_{\mathrm{DC}}$ and $I_{n}$ with APC-MFLC theory.

\subsection{Performance comparison of direct APC-PI, Indirect APC-PI and Proposed Indirect APC-MFLC}

The comparison of overall performance of proposed system are discussed in Table 3. The performance of APC- PI theory with direct and indirect current control methods are compared and found that in both conditions, the neutral current compensation is almost same but the remarkable improvement is observed in power factor, reactive power compensation and load balancing with indirect control method. It is proved through proposed simulation that the indirect current control method performance is better than direct current control for the distribution grid integrated with wind generation system. So, proposed Indirect APC-MFLC methods are suitable to compensate harmonics and reactive power, neutral current during unbalanced loading conditions. The system is capable of maintaining unity power factor as well as sinusoidal source currents. Hence, the power quality of distribution system is improved.

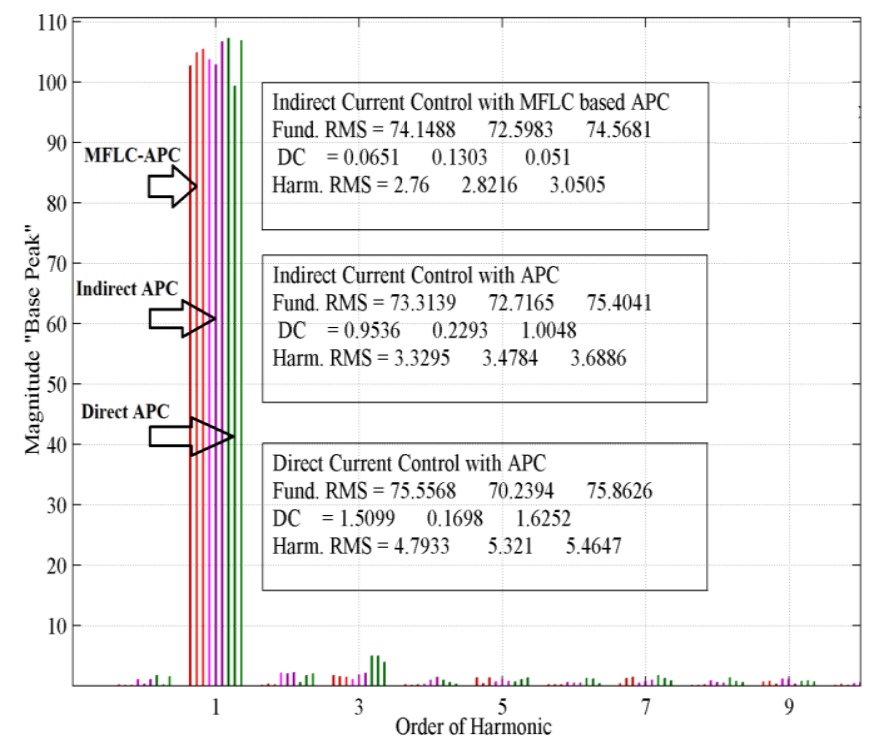

Figure 9: THD with Direct APCT-PI, Indirect APCT-PI \& Indirect APCTMFLC.

\section{Conclusion}

This paper presents a SAPF based on APC theory for reference current generation and proposed MFLC method for dclink voltage control to enhance power quality of the distribution grid integrated with wind energy source under non-linear load. The performance of APC theory with direct and indirect current control methods is compared and found that in both conditions, the neutral current compensation is almost the same but the remarkable improvement shown in power factor, reactive power compensation, and load balancing with the indirect current control method.

Table 3: Comparison of direct APCT-PI, Indirec apct-pi and indirect Apct-MFLC

\begin{tabular}{|c|c|c|c|c|c|c|c|c|c|}
\hline \multirow[t]{2}{*}{ Parameter } & \multicolumn{3}{|c|}{$\begin{array}{l}\text { Direct control } \\
\text { with APCT }\end{array}$} & \multicolumn{3}{|c|}{$\begin{array}{l}\text { Indirect direct control } \\
\text { with APCT }\end{array}$} & \multicolumn{3}{|c|}{$\begin{array}{l}\text { Indirect direct control } \\
\text { with MFLC-APCT }\end{array}$} \\
\hline & $I_{\text {sa }}$ & $I_{\text {sb }}$ & $I_{\text {sc }}$ & $I_{\text {sa }}$ & $I_{\text {sb }}$ & $I_{\text {sc }}$ & $I_{\text {sa }}$ & $I_{\text {sb }}$ & $I_{\text {sc }}$ \\
\hline Balancing of source current $I_{S}$ & 108.4 & 98.06 & 105.1 & 103.6 & 102.8 & 106.6 & 110.8 & 1.8 .1 & 108.1 \\
\hline Harmonic RMS after comp. & 4.793 & 5.321 & 5.464 & 3.329 & 3.478 & 3.688 & 2.760 & 2.821 & 3.050 \\
\hline Neutral current $I_{n}$ after amp. & \multicolumn{3}{|c|}{7.0} & \multicolumn{3}{|c|}{6.8} & \multicolumn{3}{|c|}{4.7} \\
\hline Reactive power after comp. (kVAr) & \multicolumn{3}{|c|}{7} & \multicolumn{3}{|c|}{6} & \multicolumn{3}{|c|}{3.7} \\
\hline Power Factor (PF) & \multicolumn{3}{|c|}{0.94} & \multicolumn{3}{|c|}{0.996} & \multicolumn{3}{|c|}{0.999} \\
\hline
\end{tabular}


Hence, it has been proved through a simulation study that the indirect current control loop performance is better than the direct control loop for the unbalanced distribution system. The performance of the proposed method using APC-MFLC based realized SAPF is compared to that of SAPF designed based on reported strategies such as direct APC-PI controller and indirect APC-PI controller. The simulation results show the effectiveness of the proposed control algorithms to mitigate the harmonics, compensate the reactive power, and neutral current and to improve power factor with the balancing of source current using the MATLAB/Simulink.Finally, the proposed algorithms are capable of improving power quality problems in the distribution system with wind energy sources under non-linear load.

\section{Conflict of Interest}

All authors declare no conflicts of interests.

\section{References}

[1] N. F. Mohamed, "Wind energy conversion systems, classifications and trends in application," in 2019 5th International Renewable Energy Congress," 1-6, 2014, doi: 10.1109/IREC.2014.6826922.

[2] G. Shafiullah, M. Amanullah, A. Shawkat Ali, P. Wolfs, "Potential challenges of integrating large-scale wind energy into the power grid-A review," Renewable and Sustainable Energy Reviews, 20, 306-321, 2013, doi: 10.1016/j.rser.2012.11.057.

[3] C. N. Bhende, S. Mishra, S. G. Malla, "Permanent magnet synchronous generator-based standalone wind energy supply system," IEEE Transastion Sustainable Energy, $\quad$ 2(4), 361-373,2011, doi: 10.1109/TSTE.2011.2159253.

[4] W. Xueguang, W. Weisheng, D. Huizhu, C. Yunping, "Application of Models of the Wind Energy Conversion System to Wind Power Dynamic Analysis," in 1998 IEEE Power Systems Technology Conf., Beijing, 14061411, 1998, doi: 10.1109/ICPST.1998.729318.

[5] A. S. Bubshait, M. G. Sim, A. Mortezaei, T. D. C. Busarello, "Power quality achievement using grid connected converter of wind turbine system," in 2015 1st Annu. Meeting IEEE Ind. Appl. Soc.,1-8, 2015, doi: 10.1109/IAS.2015.7356817.

[6] M. Singh, V. Khadkikar, A. Chandra, "Grid synchronisation with harmonics and reactive power compensation capability of a permanent magnet synchronous generator-based variable speed wind energy conversion system," IET Power Electronics, 4(1), 122-130, 2011, doi: 10.1049/ietpel.2009.0132.

[7] Y. Oğuz, İ. Güney, H. Çalık, "Power quality control and design of power converter for variable-speed wind energy conversion system with permanent-magnet synchronous generator," The Scientific World Journal, 2013(4), 122-132, 2013, doi: 10.1155/2013/783010.

[8] A. Bubshait, A. Mortezaei, M Simões, T. Busarello, "Power quality enhancement for a grid connected wind turbine energy system," IEEE Trans. on Industry Applications, 53(3), 2495-2505, 2017, doi: 10.1109/TIA.2017.2657482.

[9] S. Kasa, P. Ramanathan, S. Amasamy, D. P. Kothari "Effective grid interfaced renewable sources with power quality improvement using dynamic active power filter," Electrical Power and Energy Systems, 82, 150-160, 2016, doi:10.1016/j.ijepes.2016.03.002.

[10] H. Qazi, M. Wazi Mustafa "Review on active filters and its performance with grid connected fixed and variable speed wind turbine generator," Renewable and Sustainable Energy Reviews, 57, 420-438, 2016, doi: 10.1016/j.rser.2015.12.049.

[11] W. Ullah, M. Mekhilef, M. Seyedmahmoudian, "Active power filter for mitigation of power quality issues in grid integration of wind and photovoltaic energy conversion system," Renewable and Sustainable Energy Reviews, 70, 635-655, 2017, doi: 10.1016/j.rser.2016.11.091.

[12] A. Hoseinpour, S. Masoud Barakati, R. Ghazi, "Harmonic reduction in wind turbine generators using a Shunt Active Filter based on the proposed modulation technique," International Journal of Electrical Power \& Energy Systems, 43(1), 1401-1412, 2012, doi: 10.1016/j.ijepes.2012.06.052.

[13] S. Kasa, P. Ramanathan, S. Ramasamy, "Effective grid interfaced renewable sources with power quality improvement using dynamic active power filter," International Journal of Electrical Power \& Energy Systems, 82(4), 150160, 2016, doi:10.1016/j.ijepes.2016.03.002.

[14] D. Olivindo, J. A. Soa, I.R. Machado, "Shunt active power filter for energy quality improvement in distributed generation systems," in 2017 IEEE 26th International Symposium on Industrial Electronics (ISIE), 146-151, 2017, doi: 10.1109/ISIE.2017.8001238.

[15] H. Mojgan, Z. A. Abu, T. Arash, S. Mohammadsoroush "An Overview on Current Control Techniques for Grid Connected Renewable Energy Systems," 2012 2nd International Conference on Power and Energy Systems (ICPES 2012), Singapore, 119 - 126, 2012.

[16] O. F. Kececioglu, H. Acikgoz, C. Yildiz, A. Gani , M. Sekkeli, "Power Quality Improvement Using Hybrid Passive Filter Configuration for Wind Energy Systems," Journal of Electrical Engineering and Technology, 12(1), 207-216, 2017, doi: 10.5370/JEET.2017.12.1.207.

[17] M. Kouadria, T. Allaoui, M. Denai, "Power Quality improvement in isolated Wind-Diesel Power System," WEASE Trans. on Systems and Control, 12(50), 490-498, 2018, doi: 10.5370/JEET.2017.12.1.207.

[18] J. Fei, K. Ma, S. Zhang, W. Yan, Z. Yuan "Adaptive current control with PI-fuzzy compound controller for shunt active power filter," Mathematical Problems in Engineering, 2013(1), 150-158, 2013, doi.org/10.1155/2013/546842.

[19] P. Barik, G. Shankar, P. K. Sahoo "Power quality assessment of microgrid using fuzzy controller aided modified SRF based designed SAPF," International Transactions on Electrical Energy Systems, 29( 12), 1-24, 2019.

[20] V. N. Jayasankar, U Vinatha "Advanced Control Approach for Shunt Active Power Filter Interfacing Wind- Solar Hybrid Renewable System to Distribution Grid," Journal of Electrical System, 14(2), 88-102, 2018, doi:10.1002/2050-7038.12289.

[21] S.H. Qazi, M.W. Mustafa, U. Sultana "Current harmonics mitigation from grid connected variable speed due to nonlinear loads using shunt active power filter," journal Teknnology, 79(4), 2017, doi: 10.11113/jt.v79.4702.

[22] S. Ramasamy ,K. Sudheer "Enhancement of Power Quality in Renewable Source Integrated Three Phase System with ICC Controller," Journal of Green Engineering,, 8(1), 71-88, 2018, doi: 10.13052/jge1904-4720.815.

[23] K. Ramesh, G.T. Arasu "Power Quality Improvement in Wind Energy System using Seven Level shunt active power filter," Asian Journal of Technology, 17( 3), 189-196, 2018, doi:10.36478/ajit.2018.189.196.

[24] G. Arunsankar, S. Srinath, "Optimal controller for mitigation of harmonics in hybrid shunt active power filter connected distribution system: An EGOANN technique," Journal of Renewable and Sustainable Energy, 11(2), 1-16, 2019, doi: 10.1063/1.5085028. 